\title{
Gamificação no ensino de Ciências: um relato de experiência
}

\author{
Glice Rocha Pires $^{1}$, Jeanne da S. B. Bulcão ${ }^{1}$, Débora K. Silva de Azevedo ${ }^{1}$, Charles A. \\ Galvão Madeira ${ }^{1}$ \\ ${ }^{1}$ Instituto Metrópole Digital - Universidade Federal do Rio Grande do Norte(UFRN) \\ Natal - RN - Brazil \\ \{glice.rp, jeannebulcao1, deboraazevedo\}@gmail.com, charles@imd.ufrn.br
}

\begin{abstract}
The learning processes that the school offers to the students haven't been enough to avoid high levels of avoidance and disapproval. This paper aims to describe an experience about the application of gamification in teaching and learning processes in a class of the final years of Elementary School. In order to develop a design experiment using the technique of gamification, rationale and review of a series of articles on the previous topic, as well as observations, interviews and focus groups. As it was, there was a significant increase in the motivation and the sending of students investigated in the research and in the interest of one of the students of other classes, of the same school, did not investigate in the research.
\end{abstract}

Resumo. Os processos de aprender que a escola oferece aos estudantes não vem sendo suficientes para evitar índices elevados de evasão e reprovação. Este trabalho tem como objetivo descrever uma experiência sobre a aplicação da gamificação nos processos de ensino e aprendizagem em uma turma dos anos finais do Ensino Fundamental. Para desenvolvimento desta experiência, foi elaborada uma atividade pedagógica gamificada, fundamentando-se em revisão de literatura concernente ao tema anteriormente citado, assim como observações, entrevistas e grupo focal. Como resultados, foram identificados aumento na motivação e envolvimento dos alunos investigados e interesse na atividade proposta pelos estudantes de outras turmas.

\section{Introdução}

A realidade nas escolas públicas brasileiras vem desafiando educadores ao apresentar um quadro de desmotivação por parte dos alunos para se assistir às aulas. Essa é a realidade relatada por professores do sexto ao nono ano de uma escola pública estadual do Município de Macaíba - Rio Grande do Norte.

Segundo relatos dos docentes da escola, na sala de aula, os alunos não conseguem passar muito tempo na mesma atividade, queixam-se de atividades que exigem um pouco mais do raciocínio lógico em relação ao que estão acostumados, e reclamam até do fato de estarem tendo aula, pois não têm interesse no assunto abordado. Alguns deles querem conversar durante a aula inteira, e formam grupos de conversa na hora em que a professora ou outro colega está falando. Além disso, o desinteresse não é constatado apenas dentro da sala: alguns estudantes que estão no ambiente da escola apenas demonstram o desejo de não voltar para a sala após o intervalo; outros chegam a faltar com frequência.

Claramente, há uma falta de interesse por parte dos alunos em se manter compenetrados nas atividades pedagógicas. Dentro deste contexto, encontramos uma 
VIII Congresso Brasileiro de Informática na Educação (CBIE 2019)

Anais do XXV Workshop de Informática na Escola (WIE 2019)

oportunidade para a aplicação da gamificação [Deterding et al 2011] em atividades didáticas, com o objetivo de estimular, nos alunos, motivações que poderão ser transformadoras da realidade apresentada nesta problemática.

Este trabalho descreve uma experiência educativa gamificada, utilizando metodologias ativas de aprendizagem, com duas turmas do $7^{\circ}$ ano de uma Escola Estadual. O artigo visa apresentar o processo de elaboração e aplicação de uma Proposta de Atividade Pedagógica Gamificada (PAPG), que poderá servir de inspiração para a produção de soluções gamificadas de ensino em outros contextos. A proposta teve como objetivo melhorar o envolvimento e interesse dos alunos nas aulas de Ciências da referida escola, e, quando aplicada, despertou entusiasmo e sentimentos de realização nas turmas alvo da pesquisa.

\section{Fundamentação teórica}

$\mathrm{Na}$ atualidade, têm surgido com frequência metodologias de ensino e aprendizagem que trabalham na perspectiva de incentivar processos educativos mais ativos dos estudantes. Como exemplos de estratégias utilizadas nessas metodologias, podemos citar a sala de aula invertida [Bergmann \& Sams 2018], aprendizagem baseada em projetos, aprendizagem baseada em problemas, ensino híbrido [Bacich et al. 2015], [Horn \& Staker 2015] e gamificação [Fardo 2013]. Para este trabalho, lançaremos mão da última proposta.

Fardo [2013] apresenta a gamificação como uma das diversas estratégias para motivar e incentivar mudanças de comportamento dos alunos em relação às atividades escolares. Para Alves [2015], a gamificação consiste na utilização de elementos e técnicas de design de jogos em contextos diversos aos ambientes dos jogos.

A gamificação obtém êxito se for bem planejada, e se utilizados os métodos adequados para a identificação dos ativadores motivacionais que serão estimulados por meio do uso de reforços positivos e negativos. Estudos como os de Guedes et al. [2018], Ferreira [2016] e Fardo [2014] descrevem processos educativos em diferentes níveis de ensino da educação que foram estruturados e implementados utilizando gamificação. Dentre estes processos, os autores destacam o desafio em elaborar projetos que envolvam os sujeitos envolvidos, assim como apresentam como resultados o aumento no interesse e engajamento dos discentes no processo educativo vivenciado.

Entretanto, para que os projetos envolvendo gamificação possam obter êxito, é necessário utilizar estratégias e metodologias adequadas para se imergir no contexto e elaborar protótipos de soluções aplicáveis e com resultados tangíveis. Uma das estratégias que pode ser utilizada consiste no design thinking, comum em processos de criação de soluções em design.

Segundo Martins Filho [2015], o design thinking é uma metodologia difundida por Tim Brown [2010] e pode ser compreendida como uma estratégia para o desenvolvimento da criatividade e da inovação. Para Gonsales [2014], o Design Thinking direcionado para educadores é uma abordagem estruturada que tem como objetivo gerar e aprimorar ideias, a partir de cinco fases que colaboram entre si para a descoberta, compreensão, ideação, elaboração e avaliação de soluções para situações do contexto escolar. 
VIII Congresso Brasileiro de Informática na Educação (CBIE 2019)

Anais do XXV Workshop de Informática na Escola (WIE 2019)

\section{Trabalhos relacionados}

Como trabalhos relacionados à nossa pesquisa, destacamos os trabalhos de Guedes et al. [2018] com a aplicação de gamificação no ensino superior, em que apresenta como resultado a possibilidade do Projeto de Aprendizagem Gamificado (PAG) enquanto proposta didático metodológica a ser desenvolvida no contexto escolar. Medeiros et al. [2018] desenvolveram uma experiência educativa na educação básica, em turma de $9^{\circ}$ do Ensino Fundamental e indicam que a vivência oportunizada propiciou maior engajamento e motivação dos estudantes. Filho et al. [2018] traz um mapeamento com foco nas principais dificuldades relatadas pelos pesquisadores que fazem uso gamificação na educação e afirmam ser necessário um melhor planejamento na aplicação das estratégias gamificadas com o intuito de oferecer melhor interação entre os participantes e os educadores.

Os trabalhos anteriormente citados foram fundamentais para compreendermos como têm sido as aplicações práticas da gamificação na educação. Os artigos indicaram, por exemplo, o que poderíamos utilizar e como não deveríamos aplicar a nossa proposta pedagógica. Demonstraram que as principais aplicações da gamificação na educação ocorreram de forma contextualizada, porém, pontuais, sem continuidade nas escolas, por dificuldade dos professores em dar prosseguimento às experiências realizadas pelos grupos de pesquisa.

\section{Metodologia e proposta gamificada}

Como procedimento metodológico para esta pesquisa foi utilizado o Design Thinking para educadores. As etapas do Design Thinking utilizadas na pesquisa relatadas nesta seção, estão organizados nas subseções 4.1 , 4.2, 4.3, 4.4 e 4.5 a seguir.

\subsection{Descoberta}

Nesta etapa do Design Thinking, deve-se compreender o desafio e preparar a pesquisa que fundamentará as ações futuras de prototipação e experimentação. O grupo tomou conhecimento da realidade através do relato da professora da disciplina de Ciências. $\mathrm{O}$ estudo, com vistas a saber o que motivava os estudantes da escola lócus em desenvolver atividades ordinárias da vida em sociedade, tinha como objetivo identificar os ativadores motivacionais que poderiam ser explorados na etapa de prototipação para desenvolvimento da solução gamificada para aplicação junto aos alunos da escola.

Para a coleta dos dados a serem interpretados, foram utilizados quatro instrumentos de pesquisa a saber: entrevista com a professora da turma do $7^{\circ}$ onde a pesquisa foi aplicada; revisão de literatura sobre ativadores motivacionais, desafios da integração das tecnologias digitais de informação e comunicação (TDIC) ao currículo [Valente \& Almeida, 2011] e gamificação na educação [Deterding et al. 2011], [Alves 2015]; observações simples, na perspectiva de Gil [2002]; grupo focal [Morgan 1997], gravado, com 8 estudantes da turma investigada.

Por meio dos instrumentos de coleta dos dados, identificamos que os estudantes da turma investigada se sentem motivados quando: estão inseridos em um contexto em que todos os envolvidos podem ser contemplados ou atendidos em suas expectativas; 
VIII Congresso Brasileiro de Informática na Educação (CBIE 2019)

Anais do XXV Workshop de Informática na Escola (WIE 2019)

ajudam os colegas da turma; sentem-se parte de um grupo; ganham alguma recompensa; recebem feedback da professora.

\subsection{Interpretação}

Durante a fase de interpretação, deve-se entender o que significam os dados coletados por meio das estratégias de pesquisa utilizadas. Nesta etapa, o grupo envolvido na pesquisa registrou, por meio de uma ferramenta de edição de texto colaborativa simultâneo (Google Docs), anotações realizadas individual e coletivamente sobre suas impressões acerca do que puderam observar durante a atividade de observação. Após, foram realizados encontros de discussão onde cada componente expressava-se sobre o que havia percebido sobre os alunos, sobre o ambiente e sobre as regras de convivência. Neste estágio, ao discutirmos sobre os resultados dos dados, percebemos o que motivava os alunos a fazer atividades específicas e identificamos os ativadores motivacionais que podem ser utilizados no estágio de prototipação.

\subsection{Ideação}

No design thinking a ideação consiste na geração de várias ideias. Nesta etapa da pesquisa, o grupo envolvido na pesquisa reúne-se para fazer um brainstorming e são encorajados a pensar de forma expansiva e sem justificativas. Durante essa fase, foram sugeridas diversas atividades para motivar os alunos nas aulas, desde o uso de cartões para fazer reforços positivos e negativos, a práticas educativas mais ativas de ensino.

Destacamos algumas ideias que foram levantadas para serem aplicadas na fase de experimentação: o uso do aplicativo kahoot, de cartões de reforços negativos ou positivos, de tablets dos quais a escola está provida, de QR Code, e de um medidor de decibéis para controle do barulho dentro dentro da sala; produções colaborativas de artefatos, abordagens fundamentadas na aprendizagem significativa, de aprendizagem baseada em problemas e execução de atividades fora da sala de aula, e de feedback positivo.

\subsection{Experimentação}

Na etapa da experimentação, conforme aponta o design thinking, dá-se vida as ideias que possam ser aplicadas e que foram pensadas na fase da ideação. Diante disso, na experimentação construímos protótipos a fim de deixarmos as ideias anteriormente idealizadas tangíveis de serem aplicadas.

Nossa experimentação foi estruturada em uma Proposta de Atividade Pedagógica Gamificada (PAPG) para os estudantes do $7^{\circ}$ ano, sistematizada em um plano de aula, para ser aplicado pela professora de biologia da escola lócus da pesquisa. Para elaboração da proposta gamificada foi utilizado como parâmetro de criação das atividades pedagógicas os ativadores motivacionais que foram identificados na etapa de imersão e algumas ideias da fase de ideação.

O plano de aula foi organizado considerando a carga horária de 90 minutos e os seguintes elementos: introdução sobre tema da aula, execução das missões propostas e encerramento, com síntese, da aula. O tema "Biodiversidade e a classificação dos seres vivos" deveria ser apresentado, inicialmente, pela professora, por meio de uma atividade gamificada. Para a atividade, seriam projetadas imagens, de objetos que costumam ficar guardados em guarda-roupas, e um guarda-roupa; os alunos, então, 
VIII Congresso Brasileiro de Informática na Educação (CBIE 2019)

Anais do XXV Workshop de Informática na Escola (WIE 2019)

deveriam ajudar a professora na separação e inserção dos objetos nos respectivos locais no armário. Após, a professora faria uma reflexão sobre a importância de se organizar/classificar. Em seguida, a educadora projetaria às imagens de vários seres vivos e pediria para repetir o procedimento anterior. Desta vez, haveria cinco retângulos projetados (equivalente aos cinco reinos, mas sem nenhuma indicação) e os alunos teriam que encaixar cada imagem em um retângulo. Em sequência, caberia a professora explicar, rapidamente, que os seres vivos se distribuem em cinco grandes grupos.

$\mathrm{Na}$ etapa da execução das missões, os alunos deveriam ser divididos em cinco equipes, conforme os cinco reinos dos seres vivos, para realizarem as três missões a seguir:

- Missão um (10 min): cada equipe vai fazer uma pesquisa na Barsa na biblioteca da escola sobre o rei no seu grupo.

- Missão dois (10 min): pegar um cartaz que já estava na biblioteca e, de acordo com a pesquisa, descrever as principais características que definem aquele reino no cartaz.

- Missão três (5 min): sair em busca imagens dos seres vivos espalhados pela escola e trazer e colar no seu cartaz apenas os representantes daquele reino.

- Missão quatro (dois min por equipe): apresentar seu cartaz às demais equipes.

As equipes que cumprissem as quatro missões, seriam contemplados com meio ponto na média. Para o encerramento, a professora retornaria a falar, enfatizando os conteúdos principais do assunto discutidos na aula e faria o fechamento da dinâmica.

Para o feedback da experimentação, optamos por utilizar o engajamento dos alunos durante a proposta pedagógica; o relato da professora sobre a atividade, suas observações sobre o comportamento e motivação dos alunos; e escuta dos estudantes envolvidos na atividade gamificada, por meio de questões abertas, tais como: O que acharam da experiência?, O que vocês sentiram?, O que poderia ser diferente?, O que vocês melhorariam nessa aula?.

\section{Resultados e discussão}

Os recursos dos quais lançamos mão na nossa proposta mantiveram a maioria dos alunos envolvidos durante todo o tempo da aula. Com a aplicação da proposta, observamos que os alunos se mantiveram interessados, do início ao fim da aula. Contudo, o maior nível de engajamento foi notado a partir do momento em que os alunos receberam suas missões e saíram de dentro da sala de aula para outros ambientes da escola. O engajamento dos alunos durante as missões demonstra e reafirma as tendências pedagógicas que têm crescido atualmente, a saber: metodologias ativas, sala de aula invertida e gamificação.

No primeiro momento da aula, a turma estava participativa, procurando responder as perguntas feitas pela professora, mas ainda havia muitas conversas paralelas. Foi preciso algumas intervenções para dizer que haveria uma brincadeira no próximo momento e que a turma precisaria da colaboração de todos para eles concluírem a dinâmica. Observamos que houve disposição dos alunos para participar da primeira atividade após a professora perguntar se havia voluntários para usar o mouse 
sem fio, para selecionar itens dentro do arquivo PowerPoint mostrado na projeção na parede.

Percebemos que alguns dos alunos que não queriam participar estavam com uma postura fechada à proposta da docente por estarem inseguros em relação à tecnologia desconhecida por eles (mouse sem fio). Alguns na sala nunca haviam utilizado qualquer tipo de mouse. Isso reforça a ideia de que, para alimentar a motivação em um aluno, devemos prover um ambiente ou conceitos que sejam familiares a ele. Os alunos inseguros foram estimulados e, com paciência, ensinados a utilizar a tecnologia sobre a qual ainda não tinham domínio.

Todas as ações planejadas e descritas no plano de aula criado foram executadas nos dois horários disponíveis para a disciplina. Entretanto, o tempo para a missão dois e para as apresentações de cada equipe no final da aula foi muito curto, sendo constatada a necessidade de aumentarmos o tempo da aula, posteriormente, em mais dois horários para que o plano de aula possa ser cumprido sem atropelos.

Conforme a professora foi iniciando a aula, a partir da introdução do conteúdo, por meio de exposição gamificada de conteúdo sobre categorização de elementos, os alunos ainda mantiveram-se desatentos interagindo com os colegas, em diálogos paralelos. Após o segundo horário, quando a profa falou que seria a hora da atividade prática, os alunos mostraram-se curiosos. Nesse momento, foi possível perceber expectativas positivas em alguns alunos, quanto a possibilidade de vivenciarem uma atividade pedagógica diferenciada. No entanto, alguns estudantes não demonstraram empolgação com a dinâmica proposta pela professora.

Alguns destes demonstraram desânimo, enquanto questionavam se teriam de fazer um trabalho: "é pra fazer trabalho, professora?", "Vale para a nota?". O quadro mudou quando a profa explicou como seria a prática, chamando-a de dinâmica, já entregando o enunciado de introdução da dinâmica. Os alunos se concentraram em suas respectivas equipes, se aproximando uns dos outros para ler as tarefas.

Dentre os times, apenas dois alunos perderam o interesse pela atividade, e optaram por não participar dela. No entanto, os que haviam demonstrado falta de disposição inicialmente, permaneceram engajados na prática até o seu final da dinâmica.

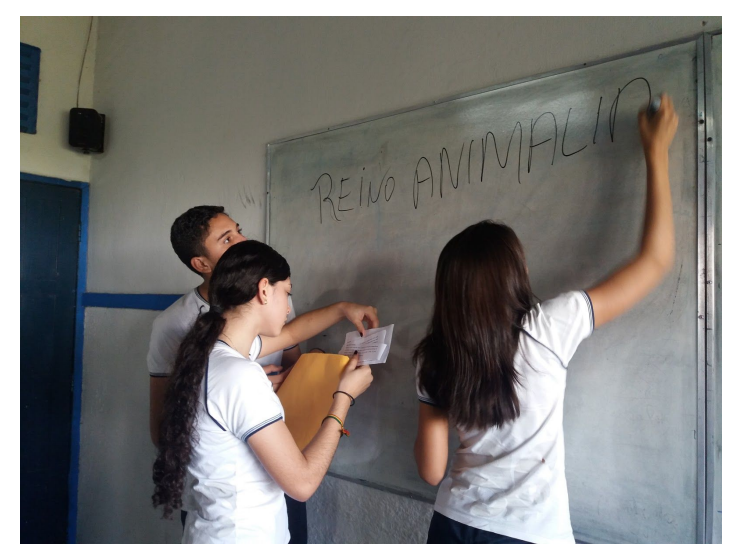

Figura 1. momento de organização dos resultados da missão1 
A aula terminou em um clima de realização, os alunos expressaram seus sentimentos com palmas para o último grupo que fez sua apresentação para a sala, e, ao tocar o sinal os alunos bateram palmas novamente e alguns chegaram a assobiar, como se estivessem em comemoração. Outro aluno, inclusive, pediu para levar o trabalho para casa para mostrar à mãe o que ele havia sido capaz de fazer. Segundo a professora, este aluno, não costuma fazer as atividades propostas em sala de aula.

Os demais estudantes apresentaram suas impressões da aula apontando que a dinâmica lhes provocaram sensações como se estivessem dentro de um jogo, ou mesmo dentro do filme missão impossível, considerando uma experiência educativa top.

\section{Considerações finais}

Os processos de ensino e de aprendizagem devem ser revisitados em um movimento contínuo de empenho e dedicação do educador e do estudante. Para que estes processos tenham maior êxito é importante que os conteúdos trabalhados em sala de aula possam ser explorados de diferentes maneiras, a fim de que o processo de aprendizagem possa ocorrer de forma mais estimulante para o estudante.

A experiência educativa relatada neste trabalho tinha como objetivo melhorar o envolvimento e o interesse dos estudantes nas aulas da disciplina de Ciências do $7^{\circ}$, assim como aumentar o engajamento durante as atividades pedagógicas. A proposta elaborada atendeu as expectativas esperadas no que concerne ao envolvimento e motivação dos estudantes na aula de Ciências. Durante a experiência educativa, a professora percebeu e externou que os alunos estavam mais engajados e atentos a dinâmica e às missões propostas na atividade gamificada da aula.

Destacamos, no entanto, que aplicação ocorreu em apenas um dia e por essa razão não podemos afirmar se o interesse e o engajamento na atividade proposta deu-se pela dinâmica presente na experiência educativa ou pela "novidade" que aula trouxe. Certamente, o que podemos dizer é que os alunos envolvidos na aula gamificada expressaram interesse, engajamento, concentração e alegria em participar da atividade proposta.

Em trabalhos futuros pretendemos ampliar as discussões desta experiência, com foco em adaptações na proposta pedagógica de atividade gamificada. As adaptações consistiram em incluir menos missões ou realizar a dinâmica em um maior período de tempo, aumentar a carga-horária para duas aulas, totalizando 180 minutos.

\section{Referências}

Almeida, M. E. B., \& Valente, J. A. (2012). Integração currículo e tecnologias e a produção de narrativas digitais. Currículo sem fronteiras, 12(3), 57-82.

Alves, F. Gamification: como criar experiências de aprendizagem engajadoras. São Paulo: DVS editora, 2015.

Bacich, L. Neto, A. T. Trevisani, F . (Orgs.). Ensino híbrido: personalização e tecnologia na educação. Porto Alegre: Penso, 2015.

Bergmann, J. Sams, A. Sala De Aula Invertida: Uma Metodologia Ativa De Aprendizagem. Rio De Janeiro: Ltc, 2018. 
VIII Congresso Brasileiro de Informática na Educação (CBIE 2019)

Anais do XXV Workshop de Informática na Escola (WIE 2019)

Brown, Tim. Uma metodologia poderosa para decretar o fim das velhas ideias design thinking. 1. ed. Rio de Janeiro: Alta Books, 2010.

Deterding, S., Dixon, D., Khaled, R., \& Nacke, L. (2011, September). From game design elements to gamefulness: defining gamification. In Proceedings of the 15th international academic MindTrek conference: Envisioning future media environments (pp. 9-15). ACM.

Fardo, M. L. A gamificação aplicada em ambientes de aprendizagem. Renote, Porto Alegre, v. 11, n. 1, p.1-9, jul. 2013. Disponível em: $<$ https://www.seer.ufrgs.br/renote/article/view/41629/26409>. Acesso em: 13 jun. 2019.

Ferreira, L., Inocêncio, A. C., Júnior, P. A. P., \& Lopes, M. M. (2016, November). Gamificação Aplicada ao Ensino de Gerência de Projetos de Software. In Anais do Workshop de Informática na Escola (Vol. 22, No. 1, p. 151).

Filho, R. S., Filho, H. A., Inocêncio, A. C. (2018, October). Um Mapeamento Sistemático sobre Fatores que Podem Influenciar na Eficiência da Gamificação. In Brazilian Symposium on Computers in Education (Simpósio Brasileiro de Informática na Educação-SBIE) (Vol. 29, No. 1, p. 506).

Gonsales, P. (2014). Design thinking para educadores. Instituto Educadigital, São Paulo. Disponível em:

$<$ https://www.designthinkingforeducators.com/DT_Livro_COMPLETO_001a090.pd f>. Acesso em 12 jun. 2019.

Morgan, DL (1997). O guia do grupo de foco (Vol. 1). Publicações sábias.

Gil, A. C. (2002). Como elaborar projetos de pesquisa. São Paulo, 5(61), 16-17.

Guedes, A. (2018, October). Projeto de Aprendizagem Gamificado: Um Relato de Experiência. In Brazilian Symposium on Computers in Education (Simpósio Brasileiro de Informática na Educação-SBIE) (Vol. 29, No. 1, p. 635).

Horn, M. B.; Staker, H. Trad. Maria Cristina Gularte Monteiro. Blended: usando a inovação disruptiva para aprimorar a educação. Porto Alegre: Penso, 2015.

Martins Filho, V., Gerges, N. R. C., \& Fialho, F. A. P. (2015). Design thinking, cognição e educação no século XXI. Revista Diálogo Educacional, 15(45), 579-596.

Medeiros, D. F., Oliveira Farias, F. L., de Lucena, D. A., Madeira, C., Santa Rosa, J. G., \& Trindade, S. S. (2018, October). Gamificação como estratégia para o engajamento de estudantes no ensino de commodities: um relato de experiência com alunos do $9^{\circ}$ ano do Ensino do Fundamental. In Anais do Workshop de Informática na Escola (Vol. 24, No. 1, p. 225). 